\title{
La recitación: el re-mix, presentando a Faith Smith y Jamaica Kincaid ${ }^{*}$
}

\author{
Diane Exavier ${ }^{1}$ \\ Smith College (EE.UU)
}

\section{Resumen}

Este ensayo parte del trabajo de las estudiosas Leah Rosemberg y Faith Smith -así como de la obra de la escritora caribeña Jamaica Kincaid y de la guionista afroamericana Suzan Lori Parks- para explorar el modo en que algunas mujeres de la diáspora han utilizado las herramientas retóricas de la recitación, la repetición y la revisión con el fin de reclamar y reposicionar una historia intelectual y literaria largamente dominada por hombres, quienes, a su vez, también han luchado por re-escribir dicha historia. ¿De qué forma estas mujeres se han apropiado de las mismas herra-

\begin{abstract}
This paper comes from the work of the scholars Leah Rosemberg, Faith Smith, and the work of the Caribbean writer Jamaica Kincaid, as well as the African American screenwriter Suzan Lori Parks. The main purpose is to explore the way in which women of the Diaspora have used the rhetorical tools of recitation, repetition, and revision, all of that with the aim of reclaiming and reposition an intellectual and literary history. This field was largely dominated by men who at their moment also fought to re-write the dominant history. -In which ways these women have re-ap-
\end{abstract}

\footnotetext{
1 "Recitation and re-mix: introducing Faith Smith and Jamaica Kincaid". Este artículo fue presentado originalmente en la II Conferencia de Teorías y Literaturas en el Caribe y Latinoamérica: "Diálogos, conexiones, historias compartidas", organizada por la Pontificia Universidad Javeriana y la Universidad del Atlántico en septiembre 2013. La traducción ha corrido a cargo de Marcelo Cabarcas, profesional en Lingüística y Literatura de la Universidad de Cartagena y candidato Magíster en Literatura Hispanoamericana y del Caribe de la Universidad del Atlántico. Recibido: 11 de noviembre de 2013 - Aprobado: 10 de diciembre de 2013 1 Master of Fine Arts in Play writing del Smith College (Northamptom, Massachusetts). Guionista radicada en New York, donde escribe e imparte clases de arte. Ha presentado trabajos en Medialia Gallery, Dixon Place, El Teatro Brick, La Internacional de Curadores Independientes y PS122, entre otras. Estudió teatro en Amherst y Smith College. e-mail: diane.exavier@gmail.com
} 
mientas que sus silenciadores han usado por tanto tiempo para elevar sus voces fuerte y claramente? ¿Cuáles son las conexiones entre las diferentes prácticas literarias que han viajado de isla en isla hasta el continente, extendiendo el alcance del archipiélago "metafísico"?

Palabras clave: creole, recitación, repetición, revisión, historia, Historia. propriated the same tools that their oppressors have used for so long to raise their voices, clear and loud against them? -Which are the connections between the different literary practices that have moved from island to island to the mainland, expanding the extent of the "metaphysical" archipelago?

Keywords: Creole, recitation, repetition, revision, story, History.

En suartículo "La audacia de Faith: las recitaciones creoles explicadas", Rosemberg (2011) aborda la obra de Faith Smith, quien, mediante la re-escritura de la biografía del escritor trinitense John Jacob Thomas, re-examina el control masculino de la historia intelectual y literaria del Caribe. Debido a que en su texto Smith utiliza el término recitación para describir su representación de la vida de Thomas, el análisis de Rosemberg inicia por la forma en que el diccionario Oxford define tal vocablo, esto es, "como un acto descriptivo o narrativo y por esa vía, como la repetición de un texto aprendido de memoria" (167). Smith, por su parte, extiende el sentido de dicha expresión a una variedad de formas que se le derivan, como recitar, re-citar y citar, conectándolo inclusive con el francés récit. Sin embargo, desde su perspectiva, tales términos, aunque estén conectados, siguen cumpliendo funciones muy distintas.

Con esta recitación de la historia de John Jacob Thomas, Faith Smith se propone re-contextualizar la formación de las identidades caribeñas: su uso de palabras e historias del pasado evidencian cuán insuficientes son el lenguaje y la terminología contemporánea. Para Smith, la historia del Caribe, según la cuentan los que hicieron la Historia (la mayúscula simboliza las fuerzas tradicionales de la opresión), y aun aquellos que hicieron historia (la minúscula combate presuntas jerarquías), excluye las palabras y experiencias de sus silenciosos e invisibles habitantes, mujeres, indios, chinos, y otras minorías que se han movido y expresado en el mismo espacio intelectual y literario del cual estos hombres se han convertido en voceros. A través de la citación y la re-citación (amén de un juego inteligente con el sentido de las palabras), Smith trae a colación la terminología propia del campo intelectual para recordarse a sí misma 
el lugar que ocupa en el mismo. Un ejemplo concreto de esto es su análisis del homónimo in sight ("a la vista"), con el cual establece la importancia de la propia visión, pues, desde su perspectiva, la historia está hecha con las manos y con los ojos de personas imperfectas que "cargan con sus pesares y cuya vista se nubla" (aunque esta ceguera varíe de acuerdo con quien se hable).

Rosemberg, al mismo tiempo, define récit como "un recuento de eventos reales o imaginarios al que muy frecuentemente se le puede traducir como relato, el cual, dependiendo del contexto, se puede denominar como de aventuras, maravilloso o histórico. Asimismo, la palabra puede significar también novela, fabula, mito o escrito historiográfico" (167). Al establecer esta conexión, tanto Smith como Rosemberg logran connotar las capacidades creativas e imaginativas de la llamada recitación, concepto que muy a menudo se asocia negativamente a la repetición de las lecciones aprendidas durante el aprendizaje de la lengua y otras herramientas del capital social. Esta asociación recuerda al profesor francés de los días de escuela de Patrick Chamoiseau, quien, en su fascinación por la belleza "convencionalizada" de lo clásico, suprimía y denigraba el uso del creole en el aula.

No obstante, si pudiese hallarse un modo de subvertir el uso de esta clase de recitación, dicho modo se convertiría entonces en un arma contra aquello que se está obligado a recitar, y como consecuencia, toda clase de puertas podrían abrirse. Algo similar intentó John Jacob Tomas con su Teoría y práctica de la gramática creole (1969), que abarca desde su fonética hasta ejemplos de proverbios y refranes cotidianos. No obstante, incluso allí, en el prefacio de su libro, Thomas hace una distinción que resulta muy difícil de olvidar entre el francés "de verdad" y el patois:

[...] volqué mi atención hacia nuestro Patois popular con el propósito de esclarecer su relación exacta con el Francés de verdad y así trazar las analogías de modificación, literales o no, que existen entre este y otros dialectos que se le derivan. Estas investigaciones, a pesar de ejecutarse en la carencia de material bibliográfico adecuado (absoluta en el caso del Creole y casi total en el caso del Francés), no fueron de ninguna forma infructíferas. Puesto que he podido dilucidar, al menos en parte, la verdadera naturaleza y estado del Creole en su calidad de idioma hablado" (iii).

En su intento de darle algún brillo (y cosechar alguna fama por ser quien lo hizo), Thomas sitúa al creole en su dimensión real, 
planteándolo como un objeto que todavía no se conoce a cabalidad, sino que está en proceso de descubrimiento. Más adelante, para la época en que aparecen los escritores de la Creolidad: Jean Bernabé, Patrick Chamoiseau y Raphaël Confiant, el juego de la recitación se ha convertido literalmente en una "plegaria" al Creole y a todo lo que éste tiene que ofrecer en su oralidad, fisicidad, intensidad, musicalidad y ritmo. En su trabajo seminal de defensa, los tres autores proclaman, con mucho fervor, que "la Creolidad tiene, aun hoy, su modo de privilegio: la oralidad [...] la oralidad creole, inclusive reprimida en su expresión estética, contiene todo un sistema de contravalores, una contracultura que ha presenciado al genio ordinario aplicarse a la resistencia, devota a la supervivencia" (1993: 95). Bernabé, Chamoiseau y Confiant parecen haber superado la explicación utilitaria de Thomas y moverse hacia una validación del creole y de su innegable poder. Pero, a pesar de toda su alabanza, terminan por enfrentarse a un inconveniente: entre líneas se puede vislumbrar la carencia de una expresión estética del creole.

En cierta forma, los creolistas nos están diciendo que el creole "es como es", evitando, al mismo tiempo, que su elogio del idioma fabrique cosas incompatibles con su propia experiencia. Estos hombres, en efecto, crecieron en una Martinica cuyo creole es solamente una expresión hablada, y esa es su verdad: saben de lo que están hablando. Lo que podría cuestionarse en su caso, no obstante es la recitación de su perspectiva, la manera en que comunican su visión de la literatura caribeña. Como Derek Walcott (1998) sostiene, en "Una carta a Chamoiseau", "nada es más afrancesado que la retórica confiada de su manifiesto. Lo cual hace eco, en todo su enfático aislamiento, de todos los panfletos que delineaban el curso de la nueva pintura, de la nueva poesía [...] ¿es el tono del Elogio de la creolidad diferente al usado en la métrica de aquellos manifiestos?" (224). En su re-mezcla de la recitación, Bernabé, Chamoiseau y Confiant caen en la trampa de intentar hacer historia en minúscula con el lenguaje de la Historia en mayúscula. Aun así, Walcott (1998) piensa diferente con respecto a la novela Texaco (1992), de Chamoiseau, con la cual se regocija:

[...] cada isla se circunscribe a esa tristeza oceánica llamada Historia, pero las histoires ${ }^{2}$ grabadas en Texaco no están relacionadas a la marcha, al ritmo de alguna cronología optimista que discurre desde la esclavitud hasta la emancipación, el colonialismo y la independencia, o al menos, la demanda por ella. Por el contrario, estos eventos son

\footnotetext{
${ }^{2}$ Walcott utiliza aquí un término francés que en español traduce "historia" o "relato".
} 
simultáneos, tienen un significado único y suceden en solo tiempo: el del sufrimiento perpetuo, la agonía habitual. El flujo del tiempo es tan simple como la reiteración de las olas o el ritmo de dos estaciones. Los habitantes de esta invasión viven en un tiempo único, el "ser y estar" de la métrica de la novela. Es esta reiteración la que incrementa la calidad del mito al rechazar los mandatos del calendario lineal: no es la Historia sino la histoire (el relato, la fábula, el rumor) lo que se opone al tiempo, a las fechas y a los lugares (219).

Esta redefinición que Walcott hace del mito trabaja de modo similar a las recitaciones pluri-significativas de Smith: de la fuerza opresiva de la $M$ mayúscula se mueve hacia una $m$ minúscula que puede ser usada como un arma contra esa misma fuerza. La recitación, con su fuerte carga histórica, se abre al concepto de récit, esa otra palabra para fábula o relato, que guarda una gran similitud con el término l'histoire. Pero, aunque las similitudes entre l'histoire y récit parecen obvias, sus diferencias sutiles resultan fundamentales, pues mientras l'histoire se asocia comúnmente al carácter comunal del rumor, récit invoca la importancia y la singularidad del recuento particular; y mientras l'histoire tal vez muestra el movimiento de los rizomas de las raíces, récit se enfoca en la madurez de una fruta única. Cada una de estas frutas singulares -vale la pena repetirlosigue proviniendo de una planta de raíz rizomática y hace el trabajo del creole con un sonido y una furia que le pertenecen del todo a esta lengua: ofrecen historias que han sido revisadas a la luz de las repeticiones alteradas, de las recitaciones de la Historia; son tiempo colapsado en el que la esclavitud, la emancipación, el colonialismo y la independencia existen en el "ser y estar" del sufrimiento perpetuo y la "habitual agonía" de la que habla Walcott. Uno de esos frutos -por dar un ejemplo- es Mr. Potter (2002), de Jamaica Kincaid, una novela que, en sus fascinantes modos diaspóricos, parecería encarnar todo lo propuesto por Smith sobre la recitación mediante un método empleado (más no inventado) por la guionista afroamericana Susan Lori Parks. Dicho método consiste en dos aspectos: la repetición y la revisión.

En sus Elementos de estilo (1995), Parks describe la "repetición” y la "revisión" como "conceptos integrales de la estética del Jazz, en la cual el compositor o músico escribirá o interpretará una frase musical una y otra vez, aunque reformulándola ligeramente con cada interpretación” (9). Así, "Rep and Rev," como le gusta llamarlos, resultan centrales para el modo en que construye las historias de sus dramas, que rechazan la linealidad, porque su forma no es compatible con su intención de dramaturga de "localizar el cementerio ancestral, 
cavar por los huesos, hallarlos, escucharlos cantar y luego trascribir su canto" (4). De modo que, mientras el trabajo de Parks en el teatro difiere del de Kincaid en la novela, ambas escritoras comparten una relación combativa con la historia, tal y como Parks lo hace notar en una de sus entrevistas: "tengo problemas con la historia porque no me sirve, y si no me sirve es porque no existe suficiente de ella" (287)

¿No es este acaso el problema de Kincaid con la Historia (y también con la historia): el hecho de que no sirva, porque no existe de ella una cantidad suficiente (entendiendo esta carencia como la ausencia de voces de las minorías que no han sido escuchadas)? ¿No es este acaso el mismo problema que Rosemberg y Smith tratan de resolver con la revisión y la recitación de la dominación masculina en la historia literaria e intelectual del Caribe? En Mr. Potter, la recitación de la vida del personaje toma un tono musical en su repetición y su revisión. Las palabras y frases se articulan una y otra vez, transformándose en versos y refranes. También son sometidas a revisión, apareciendo en formas y puntos de vista ligeramente diferentes. Mr. Potter, por ejemplo, habla con el hombre que lo ha contratado como conductor, el Dr. Weizenger, y le dice: "mi nombre es Potter, Potter es mi nombre" (Kincaid, 2002: 23). Del mismo modo, hacia al final, Elaine, la narradora, concluye con unas palabras muy similares: "Mr. Potter era mi padre, el nombre de mi padre era Mr. Potter" (195). Estos dos enunciados se reflejan el uno al otro en su apariencia y sonido; cada uno como un quiasma, con una coma en el medio de la frase, actuando como un espejo que ofrece una imagen invertida del opuesto.

Si "mi nombre es Potter" es el enunciado original, entonces "Potter es mi nombre" constituye su reflejo, una versión revisada del anterior, aunque conectada con él. Lo mismo pasa con "Mr. Potter era mi padre", aunque en verdad haya un ligero cambio en la constitución quiasmica de la frase con la adición de la palabra nombre. Al mismo tiempo, pese a que esta pequeña revisión de las palabras de Elaine apuntala lo que se podría decir sobre las palabras de Mr. Potter, lo dicho por la primera es también una referencia a la imposibilidad de una relación real entre un padre que abandonó a su hija y una hija que en el presente se encuentra revisando su propia historia. Esa imposibilidad también se entrevé en el siguiente pasaje: "y ahora soy la figura central en la vida de Mr. Potter, tal y como él lo ha sido en la mía sin que siquiera nos conozcamos" (153).

La etimología de la palabra quiasmo apunta al acto de marcar con una "X". Al usar esta herramienta gramática para encuadrar las palabras de sus personajes, Kincaid materializa, hace realidad, la relación que existe entre ellos. Pero esta relación es una negación en 
la que la "X" marca una ausencia y traza una línea desde Mr. Potter, cuyo padre no aparece en su partida de nacimiento, hasta Elaine, en cuyo certificado tampoco aparece Mr. Potter. Sin duda existe una relación en esa negación, una asociación de tipo quiásmico que repite la historia del modo más intenso y cruel. No obstante, Elaine proclama, llena de confianza, que esa línea se romperá con ella, pues "la línea espacial en la que el nombre paterno es necesario dejará de existir, y a través suyo, quienes vengan después dispondrán de un padre y de una madre y heredarán por partida doble el gran caldero de la miseria y la pequeña taza de la alegría, que son todo lo que se tiene en la vida" (101).

Este gran caldero de miseria es una reminiscencia del "sufrimiento perpetuo y la agonía habitual" que mencionaba Walcott. El parecido de Kincaid con su lenguaje e imágenes es particularmente sorprendente, sobre todo a la luz de lo que Rosenberg (2011) llama "la perjudicial falta de conexión entre las distintas generaciones, una desconexión que alguna vez hizo a Jamaica Kincaid afirmar no saber siquiera que hablar de escritores Caribeños era posible" (165). Esta semejanza temática entre la miseria abrumadora, el sufrimiento y la agonía (consciente o no) de Walcott y Kincaid le recuerda al lector la importante función que el espacio desempeña en todo esto. El espacio, como lo señala Rosenberg, demarca "el lugar físico que uno ocupa dentro de la academia" (167), pues allí se ubica la esfera intelectual desde donde se producen los debates sobre la historia y la identidad del Caribe. Pero dicho espacio, sin embargo, es también el lugar geográfico donde (y por el cual) todo este asunto sucede en primer lugar.

El espacio rodea los bordes continentales y las islas topográficamente repetidas del archipiélago "metafísico". Por esa razón, no es una gran sorpresa que Kincaid haya dicho en el año 2002 lo que Walcott ya había dicho en 1997. Y tampoco fue realmente Walcott el primero en decirlo. Ciertamente, a lo largo de las páginas de Mr. Potter, Kincaid utiliza imágenes y temas que parecen conversar con escritores caribeños como Derek Walcott, Édouard Glissant y Antonio BenítezRojo. En una de las escenas de la novela, por ejemplo, cuando Mr. Potter se encuentra con el Dr. Weizenger y su esposa May, los tres están rodeados por el agua y por "el silencio del mar (el mar está callado y sólo su propio movimiento provoca sonidos: gemidos, gritos o llantos, y tras de eso el dolor, el remordimiento y la desesperación)"(12). Casi al instante, la descripción del momento nos recuerda el poema "El mar es Historia", de Walcott (1979), donde al final: "Se hizo el sonido/ como un rumor sin eco// donde la historia realmente comienza" (28). Algo similar pasa cuando 
Nathaniel Potter, el padre de Mr. Potter, se sienta en su barco de pesca: "Al principio él estaba lleno de un sentimiento de asombro, de admiración, por la perfección del vacío" (2002: 43).

Lo anterior evoca el abismo del que habla Glissant en La poética de la relación (1997), esa imposibilidad de la nada que ofrece la posibilidad del todo: "puede decirse ahora que esta experiencia del abismo es el mejor elemento de intercambio" (8). Lo mismo sucede cuando Nathaniel Potter se asoma al final del día, e incapaz de encontrarse consigo mismo, "miró sus cestas y sus redes vacías y sintió cuán indescifrable era el mundo, cómo este no podía mantener un patrón regular [...] cómo podía caer más lluvia de la necesaria, cómo el sol podía brillar con tal ferocidad que el mundo entero podía rogar por su cese" (46). Aquí, en este momento, aparece Benítez-Rojo (1996), con el caos propio de sus islas que se repiten: "un conjunto discontinuo (¿de qué?): Condensación inestable, turbulencias, remolinos, montones de burbujas, algas deshilachadas, galeones hundidos, rompeolas, peces voladores, graznidos de gaviotas, aguaceros, fosforescencias nocturnas, remolinos y piscinas, viajes de sentido inciertos "(2).

Todas estas palabras vienen del mismo espacio creole, del mismo lugar, aunque sean vistas desde variadas perspectivas y enunciadas por voces diferentes. Estas palabras son, en el caso de Kincaid, el eco de lo que no figura en el canon y por eso no puede ser visto ni oído con claridad. No obstante, ¿qué es lo que se enturbia ante los ojos de Kincaid? ¿Qué es eso que su obra calla? Ciertamente, la recitación de la vida de Mr. Potter, un Mr. Potter que no sabe leer ni escribir, proviene de su hija Elaine, quien (a pesar de, o tal vez debido al analfabetismo de su padre) puede leer y escribir. Mientras esto pone en cuestión el punto de vista de Kincaid (su punto de vista como hija abandonada), constituye, al mismo tiempo, un recordatorio del hecho histórico de que Mr. Potter, y su padre antes que él (al igual que otros hombres similares), vivieron en un espacio sin lectura ni escritura. Volviendo a Bernarbé, Chamoiseau y Confiant (1993), a propósito de los límites del creole como expresión estética: "El creole es lo que es", Kincaid no puede, amén de una retrospectiva nostálgica, colocar una voz en el sitio donde esta no existía todavía: "¿Qué triste es nunca escuchar de nuevo el sonido de tu propia voz y, más triste incluso, nunca haber tenido una voz con la cual empezar" (189).

De esa manera, Kincaid construye su historia a partir de las herramientas que tiene a la mano: su habilidad para leer y escribir y el reconocimiento de que su padre es incapaz de hacer ambas cosas. En su continua repetición y revisión, su profunda reescritura 
de la forma y el lenguaje, y su ruptura total del tiempo y el espacio, la autora ofrece una recitación sin ningún aire de superioridad. En esta, Kincaid posiciona el relato de Mr. Potter al mismo nivel que su propia historia, al mismo nivel que la del Dr. Weizenger y Mr. Shoul y Elfrida y Annie Victoria (otros personajes de la novela). El acto simultaneo de "decir su nombre e imaginar su vida lo hacen un ser completo, ni singular ni fragmentado" (193). Es esa precisamente la tarea que el creole, o cualquier otra lengua, es capaz de ejecutar: crear un espacio, narrar una historia, y a la vez, hacer historia y todo lo que viene con ella.

\section{Bibliografía}

Benítez Rojo, A. (1996). “Introducción.” En La isla que se repite. Durham: Universidad de Duke, pp. 1-29.

Bernarbé, Jean; Chamoiseau, Patrick \& Confiant, Raphaël. (1993). Elogio de la creolidad. Paris: Gallimard.

Glissant, É. (1997). La poética de la relación. Ann Arbor: Universidad de Michigan.

Kanning, C M., \& T. Postlewait. (Eds.). (2010). Representando el pasado. Iowa City: Universidad de Iowa.

Kincaid, J. (2002). Mr. Potter. New York: Farrar, Straus, y Giroux.

Parks, Suzan-Lori. (1995). La obra americana y otros escritos. Nueva York: Grupo Theatre Communications.

Rosenberg, L. (2011). "La audacia de Faith: las recitaciones creoles explicadas", Small Axe, n 15. 2, 35, pp. 164-173.

Thomas, J. J. "Prefacio". En Teoría y práctica de la gramática Creole. Londres: New Beacon Books, pp. iii-vi.

Walcott, D. (1998): “Una carta a Chamoiseau." En Lo que dice el crepúsculo: Ensayos. Nueva York: Farrar, Straus y Giroux, pp. 213-232. . (1979). "El mar es historia". En El reino del caimito. Nueva York: Farrar, Straus, y Giroux, pp. 25-28. 
